\title{
Next-gen cancer research
}

\author{
Gregg L. Semenza ${ }^{1}$
}

Published online: 13 July 2017

(C) Springer-Verlag GmbH Germany 2017

This issue of the Journal of Molecular Medicine features outstanding review articles written by three talented postdoctoral fellows (and their mentors) whose research is supported by the American Cancer Society. Jennifer Spangle and Thomas Roberts summarize recent research that has delineated several different epigenetic mechanisms that promote cancer progression, such as hypermethylation of tumor suppressor genes and hypomethylation of genes encoding oncogenic receptor tyrosine kinases [1]. Patrick Lombardi, Michael Matunis, and Cynthia Wolberger summarize work over the last decade showing that ubiquitin and SUMO modification of chromatin at DNA double-strand breaks recruits the protein RAP80, which protects against genomic instability by regulating homologous recombination [2]. Julie Perlin, Audrey Sporrij, and Leonard Zon describe critical interactions between hemato- poietic stem cells and endothelial cells, which might be manipulated to enhance hematopoietic stem cell transplantation therapies [3]. The quality of these reviews by three up-andcoming young investigators bodes well for the next generation of cancer research.

\section{References}

1. Spangle J, Roberts T (2017) Epigenetic regulation of RTK signaling. J Mol Med (Berl). doi:10.1007/s00109-017-1559-8

2. Lombardi P, Matunis M, Wolberger C (2017) Rap80, ubiquitin and SUMO in the DNA damage response. J Mol Med (Berl). doi:10. 1007/s00109-017-1561-1

3. Perlin J, Sporrij A, Zon L (2017) Blood on the tracks: hematopoietic stem cell-endothelial cell interactions in homing and engraftment. J Mol Med (Berl). doi:10.1007/s00109-017-1559-8
Gregg L. Semenza

gsemenza@jhmi.edu

1 The Johns Hopkins University School of Medicine, Baltimore, MD, USA 